\title{
LOS SUJETOS DE LA NUEVA POLITICA SOCIAL
}

\author{
VÍCTOR GUERRERO COSSIO*
}

\section{INTRODUCCIÓN}

EL COLAPSO DEL PATRÓN de acumulación capitalista que rigió hasta fines del 60, que se caracterizó por el predominio de una economía basada en la demanda efectiva y que dio paso a socialdemocracias muy avanzadas en materia de distribución de ingresos, produjo un tipo de Estado de gran potencia e influencia sobre la sociedad. De esta situación se desprendieron políticas sociales que en Europa llevaron al Estado de Bienestar y que los países latinoamericanos intentaron reproducir, pero limitados en sus alcances debido a sus particularidades económicas, políticas y culturales.

El presente artículo plantea el ajuste de los enfoques predominantes en el anterior patrón de acumulación capitalista, que ante las enormes transformaciones sufridas en las dos últimas décadas del siglo veinte, exige a los Estados adecuaciones de las políticas tradicionales, pues éstas ya no responden a los recursos económicos existentes ni a la sensibilidad social predominante.

En este escenario, las teorías económicas capitalistas, primero la clásica, inspirada en el equilibrio natural de los factores de producción y que se expresó en el liberalismo, y posteriormente la keynesia-

Académico Universidad Arturo Prat de Iquique. Licenciado en Sociología, Magíster en Asentamientos Humanos y Medio Ambiente, y Dr. (C) Desarrollo de América Latina. E-mail: victor.guerrero@cec.unap.cl. 
na, basada en la demanda efectiva y fundante del estructuralismo, reeditan a fines del siglo veinte una antigua polémica en el mundo capitalista, pero ahora readecuada a los nuevos escenarios.

\section{LOS AJUSTES DE LAS PROPUESTAS POLÍTICAS: LIBERALIZACIÓN DE LA IZQUIERDA Y CRÍTICAS MARGINALES}

En Europa el neoliberalismo impuesto desde la década del 70 y el neoestructuralismo que se erige como su alternativa desde los 80 , para corregir los desajustes sociales producidos por el ajuste económico propiciado en el decenio anterior, han reducido las diferencias que les distinguían en sus versiones originarias, alcanzando niveles de consenso que gradualmente dejan la sensación que son lo mismo.

En la propuesta y acción política este fenómeno simbiótico genera contradicciones y paradojas, que tienden a confundir a los sujetos. Si a nivel de los discursos aún se plantean diferencias importantes en las políticas sociales, a nivel de los hechos éstas casi desaparecen, conflicto que los sectores que representan al progresismo a veces resuelven con esmirriados logros en aspectos materiales, relativa promoción de la participación social y con iniciativas ideológicas, especialmente a través de campañas publicitarias masivas.

Las limitadas capacidades económicas de ambos enfoques del desarrollo predominantes en el fin de siglo veinte, han fracasado en sus promesas sociales, desvirtuando sus prácticas frente a las expectativas de la población y provocando un distanciamiento de sus referentes políticos que se expresó, primero en una negación de los regímenes neoliberales y posteriormente en un abandono de las corrientes socialdemócratas, que en este último caso causó una decepción colectiva ante el incumplimiento de las expectativas. En este último caso, algunos sectores históricamente ubicados en la izquierda chilena han adoptado una posición de crítica sistémica a las desigualdades producidas por el orden capitalista de mercado.

Este fenómeno sociopolítico, en el marco de una ausencia de alternativas extrasistémicas claras, permitió la actualización de la promesa capitalista a los nuevos sujetos sociales, condicionada a propuestas políticas que sintonizaran mejor con la nueva sensibilidad social y desde allí a los aspectos socioeconómicos, planteados como temas de la gente o «cosismo». Las ideas novedosas y más cercanas al sentido común de los nuevos sujetos, que ambos enfoques debieron 
asimilar, provinieron del posmodernismo, acercando los niveles —antes distanciados - de la formulación, la aplicación y la recepción de las políticas sociales.

En este escenario aparecen ciertos antagonismos entre posiciones tradicionales y liderazgos emergentes, más cercanos a la nueva sensibilidad y que expresan fenómenos conocidos como outsiders, que actúan en los márgenes de los bloques políticos oficiales y frecuentemente criticando a posiciones oficiales, aunque el contrapunto esté referido a temas no fundamentales de su proyecto político.

Estos marcos políticos también han conducido a liderazgos de corte populista, tanto de izquierda como de derecha, y que cuentan con espacios al interior de los partidos políticos, aunque sus fricciones son mayores. En todo caso las corrientes liberales tienen favorables condiciones para adecuarlas y transmitir de manera más atractiva las ideas posmodernas para la ciudadanía.

\section{POLÍTICA SOCIAL Y NEOLIBERALISMO EN CHILE}

Desde mediados del 70 la sociedad chilena ha sido objeto de importantes transformaciones, derivadas del nuevo patrón de acumulación impuesto en Chile desde el golpe de Estado y de la consolidación del modelo neoliberal a nivel mundial. Desde ese período y hasta la década del 90, la población chilena fue objeto del ajuste promovido desde las instituciones rectoras del orden mundial -FMI y Banco Mundial- que tendieron a enfatizar las políticas económicas y reducir las políticas sociales.

Las políticas sociales surgidas desde la óptica neoliberal se basaron en el individuo, el mercado y la dimensión material, por sobre la colectividad, el Estado y la dimensión espiritual. En este marco analítico se definió la pobreza, concepto fundamental para dimensionar y direccionar el carácter de la política social, desde un punto de vista economicista, material e individual, semejante a las elaboraciones teóricas y prácticas producidas en los países centrales que difundieron la sociedad de mercado, especialmente Estados Unidos e Inglaterra, ambos de fuerte influencia en Chile.

Los enfoques teóricos derivados del neoliberalismo exacerbaron la eficiencia como fundamento de sus políticas, subordinando las cuestiones sociales a las necesidades del ajuste económico, a fin de liberar al Estado de los compromisos contraídos durante la vigencia del Estado de Bienestar. 
La primera versión del neoliberalismo, sustentado en expresiones políticas autoritarias, a la manera de Thatcher en Inglaterra y Reagan en Estados Unidos, tuvo manifestaciones más cruentas en América Latina y se sostuvo en regímenes dictatoriales que encontraron en las Fuerzas Armadas su pilar decisivo para imponer las políticas regresivas en materia de participación y distribución del ingreso.

En Chile cobra particular importancia y nitidez la base militar del ajuste económico y político, traducido en costos sociales de enorme magnitud. Esto tuvo sus razones de índole general asociadas al patrón de acumulación desarrollista y particulares en tanto se había producido el acceso al gobierno de una fórmula de democracia avanzada como era la Unidad Popular.

La segunda versión del neoliberalismo, que muestra una cara progresista y de modalidad estética posmoderna, se refleja en la figura de Lavín, quien se apoya en las ideas del cambio y la libertad, que no se pudieron imponer en el régimen militar por las características genéticas de éste, como también por sus prácticas que atentaban contra un imaginario obrero de acceso a participación y beneficios económicos.

Esta versión más favorecida en lo estético por la ideas posmodernistas, viene a disputar la adhesión de los ciudadanos en la respuesta a necesidades y demandas a la propuesta neoestructural conocida como tercera vía, la que limitada por un orden económico estricto no puede separarse drásticamente de las políticas sociales impuestas por el neoliberalismo ortodoxo.

\section{POLÍTICA SOCIAL Y NEOESTRUCTURALISMO EN CHILE}

Al comenzar la década del noventa, Chile inicia un proceso de transición a la democracia, luego de una larga y difícil negociación con el régimen militar. En estos años sus propuestas, expresadas en el programa de gobierno de la alianza política que desplazó al militarismo, contenían ideas de políticas sociales que evidenciaban una clara diferenciación con las que habían regido en la década del ochenta.

Sin embargo, en la década del noventa, junto al acceso de expresiones democráticas concertadas en la actual alianza de gobierno, se comienza a advertir el giro desde las posiciones de la derecha asociada al militarismo hacia expresiones mas civilistas y libertarias.

Al término de la década de los noventa, en el escenario que presenta el fin de siglo, la derecha renovada, cada vez más cerca del neopopulismo, avanza más en la adhesión de los ciudadanos. Éstos 
ven más respaldo a sus demandas en quienes se alejan de los conflictos valóricos y derechos humanos, sustentándose más bien en las necesidades concretas.

La verdad es que se trata más bien de una especie de alejamiento de posiciones o discursos de corte racional burocrático que no anuncia soluciones de corto plazo ni acorde a los distintos intereses elaborados en el Chile de fin de siglo. La nueva derecha, en su cara civilista y libertaria, se aproxima más a la imagen diversificada del Chile actual que la concepción más totalizante y homogénea que trasunta la política oficial del gobierno.

\section{POLÍTICA SOCIAL Y NUEVA CUESTIÓN SOCIAL}

Las fricciones entre el Estado y la sociedad civil, derivadas de las transformaciones estructurales suscitadas en los últimos treinta años, terminaron por derrumbar las instituciones y la sensibilidad social que habían cristalizado en la sociedad desarrollista de mediados del siglo veinte.

Después de un relativamente breve dominio de fórmulas neoliberales ortodoxas, vigentes en los países desarrollados desde la década del 70 e instauradas en América Latina desde los 80, se transitó a un orden dominado por fórmulas socialdemócratas renovadas, que en esencia administran de manera socialmente menos cruenta el modelo neoliberal.

Si bien es cierto la socialdemocracia de los 90, en su versión conservadora como es la conocida Tercera Vía, admite un papel más decisivo del Estado a fin de atenuar las perversiones sociales del mercado, en materia de políticas sociales sus variaciones no son tan decisivas ni profundas, lo que se advierte especialmente en que la definición de pobreza y las maneras de enfrentarla no sufre mayores cambios.

Quizás la discusión a fondo de la cuestión social, es decir las necesidades y demandas producidas en el mundo del trabajo, tal como ha ocurrido en todo punto de inflexión de la sociedad capitalista en sus grandes momentos de modernización, no se ha producido por la incapacidad intrínseca del sistema capitalista para producir modelos alternativos intrasistémicos. A la vez, por la inexistencia de opciones extrasistémicas como fue el caso del socialismo que existió en Europa Oriental.

Las posibilidades de que exista una redefinición de conceptos 
principales pasa por la existencia de posiciones diferentes tanto teóricas como prácticas, que en el caso de la respuesta neoestructural que sucede a la posición neoliberal ortodoxa no sucede de manera clara y profunda. El consenso en materia económica producido en estas supuestas tendencias teóricas opuestas conduce a implementación de políticas sociales semejantes, puesto que una mayor radicalidad pondría en cuestión el orden económico, lo que no está en la agenda de los administradores del modelo actual.

En este sentido, las posibilidades para una actualización de la cuestión social vigente en el escenario de modernización existente en el mundo desde la década del 70, concerniente a las tensiones producidas en la población asalariada no se han podido realizar, dada la similitud de diagnóstico y formulación de políticas que mantienen los enfoques teóricos en que se basan los sectores políticos dominantes. En este caso hay mucha diferencia respecto al escenario de oposición en que coexistían el liberalismo y el desarrollismo durante las décadas del 40 al 70.

La similitud de diagnóstico en materia económica del enfoque neoliberal y de su alternativa, el neoestructuralismo, reduce las posibilidades de formulación de políticas sociales claramente diferentes, revelando que discutir las características de la nueva cuestión social no es una tarea urgente ni necesaria, mas aún, resultaría tensionante y difícil de asumir en el orden económico actual.

La sociedad actual, sometida al desempleo estructural, a la disminución de tributos privados al Estado, a la inequitativa distribución del ingreso, que produce creciente exclusión social, adquiere carácter sistémico y redefine las relaciones sociales. En este sentido las políticas sociales no se ponen a la altura de los fenómenos actuales y no alcanzan a resolverlos, aun en las sociedades nacionales más progresistas.

\section{POLÍTICAS SOCIALES: NUEVOS ENFOQUES Y PROPUESTAS}

Si bien en la Comunidad Europea se instituye la semana laboral corta, repartiendo más equitativamente los empleos que se alcanzan a producir en la economía tecnologizada actual, los fenómenos de desintegración social y violencia étnica comienzan a prevalecer por sobre los aspectos favorables del orden actual. Por su parte en Estados Unidos, donde no hay decisión mayoritaria de socializar mas inclusivamente el ingreso, se promueve una política social de índole represi- 
va asociada a la denominación Tolerancia Cero.

Las dos realidades anteriores, de obligada referencia para las sociedades nacionales de todo el mundo y particularmente para Chile, tienen sus expresiones por parte de distintos actores sociales e institucionales. Así, en el caso de los trabajadores se han conocido propuestas de la Central Unitaria de Trabajadores de disminuir la jornada laboral semanal, a diferencia de sectores empresariales que rechazan esta opción sosteniendo no estar acorde a la realidad nacional. En el caso de los actores estatales se advierte una disputa entre promotores de la semana corta V/S tolerancia cero, donde aprecia un predominio de las políticas represivas.

Esta disputa revela en el fondo, constituyendo un importante indicador de la definición de políticas sociales, la contradicción existente entre el peso de las políticas económicas y las sociales, la que se dirime a favor de las primeras. Desde una lectura crítica tal definición se enmarca en una restricción estructural a la ampliación de los beneficios sociales, o dicho de otra manera, una difusión de los ingresos.

La nueva cuestión social, que revela la actual composición de las relaciones sociales y su atención por parte del Estado, indica que tiende a ser conceptualizada más desde una perspectiva conservadora y heterogeneizante en extremo, donde cobra sentido la expresión liberalizante, perdiendo de vista las colectividades y el goce de beneficios sociales que la humanidad ha valorado y legitimado como bienes esenciales. Esta disputa, que en los países centrales ha tenido expresiones restrictivas como es el caso del modelo anglosajón, fundamentalmente economicista, y la opción francesa, más inclusivo y socializante, también se representa en los países dependientes, como es el caso chileno.

En este nivel de análisis es relevante fijar la atención en la polémica académica, trasladada a discusión de políticas, por parte de dos destacados autores franceses, Robert Castells y Pierre Rosanvallón, que representan dos pensamientos diferentes y recientes en cuanto a definir e intervenir en la exclusión social. El primero de ellos presenta el problema desde un punto de vista multidimensional, de responsabilidad pública. El segundo más bien lo centra en la dimensión económica y de atención más individual. Las ideas de política social resultante son amplias y profundas en el primero de los casos, mientras que aparecen más restringidas y superficiales en el segundo de ellos.

Ante esta realidad compleja, el tratamiento de los problemas sociales tiene restricciones tanto intra como extra nacionales, es decir, 
se transita tanto en la globalización como en la particularización, resultando de esta relación conflictiva aspectos contradictorios resueltos con políticas limitadas y legitimación en base a ideologías.

Una contradicción evidente —o paradoja — es que los sectores neoliberales que revisten su discurso con elementos ideológicos provenientes del posmodernismo, les permiten introducir de manera más atractiva fórmulas evasivas del Estado bajo el pretexto de atender la libertad y la diversidad.

Al mismo tiempo, las fórmulas neoestructurales en el marco de una política económica adversa, presentada como exclusiva, intentan aliviar los costos sociales con fórmulas que recuperan la participación y los intereses colectivos, pero el imaginario les acerca a las concepciones homogeneizantes de la sociedad de los 60, al mismo tiempo que sus fórmulas participativas y descentralizadoras les funcionalizan a la economía neoclásica, pues descargan sobre los esfuerzos de la población las soluciones a los déficits sociales. Esto último entrega argumentos a críticas de quienes les señalan como administradores del neoliberalismo.

\section{NUEVA POLÍTICA SOCIAL, LA FOCALIZACIÓN DEL GASTO SOCIAL}

De inmensa relevancia en la definición y práctica de la política social es la orientación del gasto social, que marca un carácter central de la acción pública de los gobiernos. En este sentido es notoria la diferencia entre las teorías y prácticas existentes hasta la década del 70 y las que se imponen desde los 80 hasta la actualidad.

Así en Chile, un tema importante, que a la vez define en importante medida el carácter de la política social implementada durante 15 años, fue la focalización del gasto social, congruente con la política subsidiaria del Estado, promovida por el régimen militar, y acorde a sus inspiraciones teóricas y prácticas neoliberales.

Este enfoque terminó con la política social de corte universalista, la que se inspiraba en tradiciones teóricas y filosóficas firmemente arraigadas en la sensibilidad del pensamiento moderno. Sin embargo, éstas daban cuenta de un tipo de sociedad homogénea, compacta, de menor intensidad y velocidad del cambio, escenario en el cual resultaban plausibles dichas acciones públicas.

El carácter de la sociedad actual, los desajustes económicos y sociales producidos por el neoliberalismo, la emergencia de la pro- 
puesta neoestructural, y el consenso en materia de política económica, limitan las posibilidades de la acción pública transformadora, originando contradicciones y paradojas entre el discurso y la práctica pública. Estas condiciones objetivas y subjetivas se imponen a las propuestas sociales y transforman, funcionalizándolas, a las necesidades y potencias del orden social.

De este modo pueden explicarse las súbitas transformaciones de propuesta pública, expresado como programa de gobierno, en el caso de la República Argentina en el primer período de Menem, el incumplimiento del programa de gobierno en el caso de Chile desde el gobierno de Aylwin y también en este país en el contraste advertido entre las expectativas de Lagos y las posibilidades reales de que éstas se cumplan.

Las limitaciones derivadas del consenso existente en cuanto a la política económica en el actual orden social, han determinado que los ejes centrales del diseño público impuesto por el neoliberalismo permanezcan como rectores aun cuando sus regímenes ortodoxos hayan sido desplazados por propuestas inspiradas en la nueva socialdemocracia, o tercera vía.

El carácter del Estado, la política internacional, el origen y valorización del capital, hacen que la política pública no pueda sufrir grandes transformaciones, constituyéndose tanto en trabas institucionales como prácticas de las relaciones sociales, determinado una nueva sensibilidad social, un nuevo sentido común. Esto se expresa claramente en que una de las mayores paradojas y contradicciones sea que la alternativa transformadora, sobre la cual existían grandes expectativas para superar los rigores del ajuste neoliberal, no redefina el concepto de pobreza, manteniendo la política de focalización y justificándola en la diferenciación social creciente acorde al nuevo carácter de la sociedad.

La idea subsidiaria de reducir la acción hacia los grupos sociales extremadamente débiles, de acuerdo a la lógica del Estado mínimo, se reproduce en administraciones discursivamente más progresistas en el marco de la sociedad diversa. A la vez, esta definición comienza a expresar nuevos temas de la cuestión social, como es el caso de las clases medias que se excluyen de la atención directa del Estado.

\section{DIVERSIFICACIÓN DE LA SOCIEDAD, FRAGMENTACIÓN DE LAS POLÍTICAS}


El cambio en la sociedad del trabajo, junto a las dinámicas desarrolladas por los influjos de la globalización, han conducido a una diversificación de las demandas. Así, el enfoque basado en las demandas de los trabajadores, junto a la disminución de éstos, al desempleo estructural, al empleo informal y a la emergencia de movimientos sociales que reivindican intereses extralaborales, hacen que se contraponga el tema de la universalización, la focalización y la diversidad debido a la multiplicidad de los actores sociales (género, indígenas, jóvenes, ancianos y otras minorías o grupos sociales discriminados).

Las nuevas características de la sociedad, junto a los desajustes sociales producidos por las políticas de ajuste económico realizados por el neoliberalismo, han producido un cuadro social que se confronta con los dos enfoques del desarrollo predominantes en el mundo: el de focalización y el de universalización, el primero por enfatizar la atención hacia los grupos extremadamente débiles y el segundo por tender a soluciones totalizantes, que chocan con la naturaleza más particularizada de la realidad social.

Frente a las perversiones sociales del neoliberalismo y a las limitaciones de política posibles de implementar por el neoestructuralismo, ambos enfoques han comenzado a adoptar algunas ideas provenientes de corrientes posmodernas, haciendo que sus discursos tengan una estética más favorable y faciliten la adhesión a sus propuestas.

En la inserción de las ideas posmodernas, es la concepción neoliberal la que tiene mejores condiciones para su asimilación en el discurso, pues el sentido común existente sintoniza mejor con las ideas de la libertad que de la igualdad. De esta manera las propuestas elaboradas en los últimos diez años han revitalizado a quienes insisten en los principios de la economía neoclásica, por sobre los que tratan de adecuar el keynesianismo a un orden económico no favorable.

Las ideas de la descentralización, de la desconcentración, de las preferencias individuales y prácticas, en vez de las necesidades colectivas y esenciales, la participación y el cambio, son orientados y hechos funcionales a la perspectiva economicista. Por el contrario, el enfoque alternativo, dado el imaginario existente frente a quienes enfatizan el rol del Estado, son advertidos como conservadores y autoritarios, perdiendo gran parte de su legitimidad. Si es así en el plano de la subjetividad, también en los planos objetivos esta perspectiva queda en desventaja, pues se intenta redistribuir con un Estado débil en términos políticos y financieros, además que carece de sentido estratégico al eliminar el componente de los proyectos nacionales de desarrollo 
y con ello de avanzar hacia la autonomía e independencia económica y política.

En todo caso, estas contradicciones requieren un esfuerzo para promover una mejoría en el desarrollo social, a través de instrumentos de política que consideren tanto la transformación real y profunda de la sociedad, como la emergencia de nuevos y potentes actores sociales. Estos últimos requieren una discusión profunda acerca de la nueva cuestión social, proceso que podría favorecer la relación entre la propuesta neoestructural — de raíz igualitaria— - y el carácter diverso de la realidad social actual.

Estos procesos sociales, tanto objetivos como subjetivos, han derivado hacia una situación que trasciende el carácter instrumental de las políticas sociales, alcanzando el nivel de la política mayor e incidiendo directamente en las propuestas de gobierno, como ha sido el caso en los últimos eventos electorales ocurridos en Chile, que muestran cómo el discurso estéticamente atractivo de la derecha neopopulista tiende a arraigarse en el sentido subjetivo de la población, haciendo que viejas ideas y políticas, rechazadas otrora, en la actualidad sean aceptadas y advertidas como favorables. Esto equivale también a decir que las propuestas políticas que antes eran consideradas conservadoras ahora son progresistas, y viceversa.

\section{NEOPOPULISMOS: POLÍTICAS COSISTAS, UN RIESGO PARA LA DEMOCRACIA}

La crisis social suscitada por la profunda transformación de la sociedad, las dificultades para elaborar modelos alternativos al enfoque económico dominante, la insuficiente discusión acerca del carácter actual de la cuestión social y por ende la continuidad de las principales definiciones teóricas en que se basan las políticas sociales, han llevado a que los modelos de desarrollo social existentes hayan recurrido a ideas provenientes del posmodernismo para presentarse con una estética más atractiva y cercana al imaginario actual.

En este marco las posturas neoliberales resultan favorecidas en este esfuerzo e interés por asimilar las concepciones progresistas, más aún cuando el enfoque alternativo se enfrenta a contradicciones en sus políticas, dadas por la tradición teórica y las consecuencias prácticas que trae consigo dicha concepción al implementar políticas en una sociedad altamente transformada, particularmente por la emergencia de actores sociales nuevos o potenciamiento de otros ya exis- 
tentes.

El fenómeno que trae consigo esta asimilación teórica y práctica ha conducido a propuestas de corte neopopulista, alternativas a tipos de autoridad racional-legal que caracterizan a los regímenes políticos oficiales. Estos últimos son asimilados a colectividades tradicionales que carecen de viabilidad objetiva — por un problema de recursos- y también de validez subjetiva — pues se distancian de la sensibilidad actual - convirtiéndose en entidades que no dan confianza.

En cambio, la propuesta populista tiene virtudes imposibles de encontrar en los partidos políticos, pues se caracteriza por establecer una relación íntima, mágica, específica y estratégica con el pueblo, a quien interpela. Asimismo, se confronta con los poderes centralistas del Estado y de la sociedad, enfatizando los intereses cercanos del pueblo a quien conduce en sus luchas por acceder a los beneficios, contando en suma con mayor sentido de la localidad y las demandas prácticas.

Ciertamente, esta tendencia a los liderazgos populistas constituyen un riesgo para la democracia, pero a la vez es una respuesta de la sociedad frente a un Estado débil y a una tecnocracia lejana a los intereses y códigos culturales de la ciudadanía. El punto es cómo alcanzar una institucionalidad y comunicación más valedera que sea más eficiente que los métodos hoy repudiados por la población, más dependiente de habilitación social.

IQUIQUE, JULIO DEL 2001

\section{BIBLIOGRAFÍA}

URzÚA, RAÚl (editor) (1997): Cambio social y políticas públicas. Santiago: Centro de Análisis de Políticas Públicas, Universidad de Chile.

BAUMAN, ZYGMUNT (1999): La globalización. Consecuencias humanas. México: FCE.

Hinkelammert, FrANZ (2001): El nihilismo al desnudo. Santiago: LOM Ediciones. 